\title{
ScIDice
}

\author{
International Journal of Dentistry and Oral Science (IJDOS) \\ ISSN: 2377-8075
}

\section{Assessment Of Relationship Between Periodontal Disease And Pregnancy- A Retrospective Study}

Research Article

\author{
Ashfaq Ahmed $\mathrm{M}^{1}$, Deepika Rajendran ${ }^{2 *}$, Saravana Dinesh.S.P ${ }^{3}$
}

${ }^{1}$ Saveetha Dental College and Hospitals, Saveetha Institute of Medical and Technical Sciences, Chennai - 600 077, TN, India.

${ }^{2}$ Senior Lecturer, Department of Oral Medicine and Radiology, Saveetha Dental College, Saveetha Institute of Medical and Technical Sciences, Saveetha University, 162, Poonamallee High Road, Chennai - 600077, Tamil Nadu, India.

${ }^{3}$ Professor and Head, Department of Orthodontics and Dentofacial Orthopedics, Saveetha Dental College, Saveetha Institute of Medical and Technical Sciences, Saveetha University, 162, Poonamallee High Road, Chennai - 600077, Tamil Nadu, India.

\section{Abstract}

Periodontal disease is one of the most common chronic disorders of infectious origin known in humans. Adverse pregnancy outcomes that have been linked to periodontal disease include preterm birth, low birthweight, miscarriage or early pregnancy loss, and pre-eclampsia. Changes and increase in sexual hormones during pregnancy affect different organs and produce an alteration of the immune system Pregnancy hormones cause changes in gingival environment by increasing plaque retention leading to pregnancy related gingivitis/periodontitis. Thus the aim of the study was to assess the relationship between periodontal disease and pregnant women. The details of the patients were obtained from patients records that are formulated in an institutional setting. Data was downloaded and imported to excel sheet. The excel sheet was imported to spss software 23 and the results were obtained in the form of graphs and tables. From the results obtained we found that out of 55 subjects, patients of age group 26- 30 years(29.09\%) were more commonly affected with periodontal disease and women of age group 31-40 years $(10.91 \%)$ were the least affected and the results obtained were statistically significant $(\mathrm{p}<0.05) .22$ patients who were in the 2 nd trimester $(40 \%)$ were prevalent to develop periodontal disease during their gestation period and women in the 1 st trimester were the least affected $(5.45 \%)$ and the results obtained were statistically significant. Thus it is important to make the pregnant patients understand about the ill effects of the periodontal disease on pregnancy with various complications associated during the gestational period and maintain a good oral hygiene to prevent destruction of the periodontium.

Keywords: Hormones; Gingivitis; Pregnancy; Periodontal disease; Trimester.

\section{Introduction}

Periodontal disease is one of the most common chronic disorders of infectious origin known in humans [1]. Periodontal disease refers to destruction of supporting structures of the tooth initially commencing with gingivitis gradually progressing to extensive destruction called periodontitis [2]. Periodontal disease is initiated by overgrowth of certain bacterial species, with a majority of Gram negative, anaerobic bacteria growing in subgingival sites [3]. The host response to periodontal pathogens causes persistent inflammation and the destruction of periodontal tissues that support teeth, [4] leading to clinical manifestations of disease. There are evidence suggesting associations between periodontal disease and increased risk of systemic diseases such as atherosclerosis, myocardial infarction, stroke, diabetes mellitus, and adverse pregnancy outcomes [5]. It is essential to practice good oral hygiene habits in order to maintain optimum oral health [6]. Adverse pregnancy outcomes that have been linked to periodontal disease include preterm birth, low birthweight, miscarriage or early pregnancy loss, and pre-eclampsia [7]. A confirmation of periodontal disease as an independent risk factor for adverse pregnancy outcomes would be of great public health importance because periodontal disease is both preventable and curable. Improving periodontal health before or during pregnancy may prevent or reduce the occurrences of these adverse pregnancy outcomes and therefore reduce the maternal and perinatal morbidity and mortality [8].

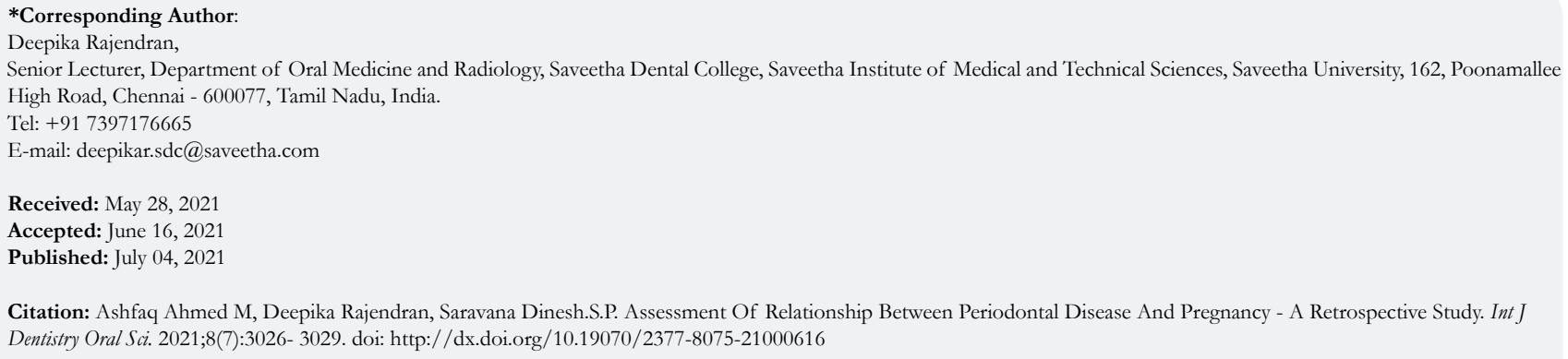

Copyright: Deepika Rajendran ${ }^{\circ} 2021$. This is an open-access article distributed under the terms of the Creative Commons Attribution License, which permits unrestricted use, distribution and reproduction in any medium, provided the original author and source are credited. 
Changes and increase in sexual hormones during pregnancy affect different organs and produce an alteration of the immune system. Gingival tissues are influenced by physiological changes in serum concentrations of female sex hormones during gestation, producing some degree of gingival oedema and gingivitis. The bacterial composition is itself modified by increased progesterone levels that favour the development of Prevotella intermedia. These factors may account for the increased gingivitis during pregnancy, with characteristic interdental tumefaction or even epulis [9]. Vitamin $\mathrm{C}$ has anti inflammatory properties that can reduce the effects of periodontal disease and it is highly recommended for pregnant and lactating women [10]. Previously our team has a rich experience in working on various research projects across multiple disciplines [11-25].

Thus the aim of the study was to assess the relationship between periodontal disease and pregnant women.

\section{Materials And Methods}

A single centre retrospective study was done in an institutional setting. The ethical approval was received from the institutional ethical committee. The study involved selected pregnant patients data who reported to the clinic for dental treatment. The necessary approvals in gaining the data were obtained from the institutional ethical committee (SDC/SIHEC/2020/DIASDATA/0619-0320).

\section{Selection of Subjects}

All patients who are pregnant and reported to the clinic from the time period of June 2019 to April 2020 were selected for the study $(\mathrm{N}=55)$. All available data were taken into consideration and there was no sorting process.

\section{Data collection}

The patients details were retrieved from the institution's patient record management software(Dental information archiving software) Data regarding patients age, gender, medical condition, Pregnancy trimester and periodontal condition were taken into consideration for this study. Cross verification was done with the help of photographs and radiographs. The data was manually verified, tabulated and sorted.

\section{Inclusion criteria}

All patients who were pregnant were taken into account.

\section{Exclusion criteria}

Patients' records that were incomplete were removed from the study and repetitive entries were also removed. Factors such as Patients with medical history, Patients on medications, Previous history of periodontal disease, Loss of tooth due to caries were also excluded from the study.

\section{Statistical analysis}

The tabulation of data was analysed using SPSS software (IBM SPSS Statistics version 23.0) The method of statistical analysis that was used in this study was Chi square test to compare two proportions. The analysis was done for age, Pregnancy trimester, Periodontal disease in this study.

\section{Results And Discussion}

It was observed from our study that among the 55 patients, $35 \mathrm{pa}$ tients $(63.64 \%)$ had periodontal disease and 20 patients(36.36\%) had healthy gingiva (Figure 1). Among the 55 patients, there were 7 patients(12.73\%) in the 1 st trimester and 29 patients $(52.73 \%)$ in the 2nd trimester and 19 patients $(34.55 \%)$ in the 3 rd trimester. Majority of the patients were in the 2nd trimester(figure 2).

Among 55 patients, 3 patients $(5.45 \%)$ in 1 st trimester had periodontal disease and 22 patients(40\%) in the 2 nd trimester had periodontal disease and 10 patients $(18.18 \%)$ in the 3 rd trimester had periodontal disease. Women in the 2 nd trimester were more prevalent to have periodontal disease than other stages of pregnancy. $P$ value: $0.024(p<0.05)$ hence statistically significant proving the association between pregnancy trimester and periodontal disease (Figure 3).

Among the 55 pregnant women, 23 patients belong to age group of 18-25 years in which 13 patients(23.64\%) had periodontal disease and out of 22 patients in age group of 26-30 years, 16 patients $(29.09 \%)$ were affected with periodontal disease and out of 10 patients in age group of 31-40 years, 6 pregnant women had periodontal disease. Patients of age group 26-30 year were more

Figure 1. Bar graph represents total number of pregnant patients with presence/absence of periodontal disease. $\mathrm{X}$ axis represents presence/absence of periodontal disease and $\mathrm{Y}$ axis represents total number of pregnant patients. Among 55 patients, 35 patients $(63.64 \%)$ had periodontal disease.

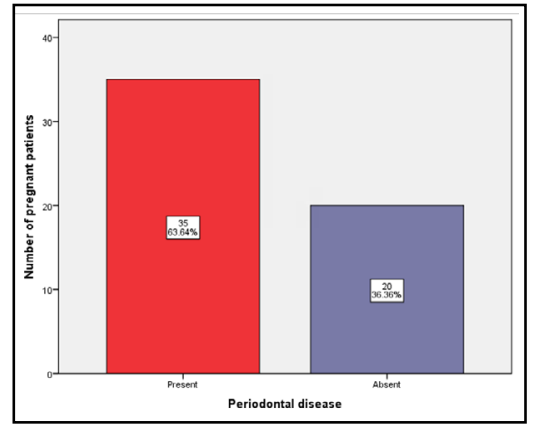


Figure 2. Bar Graph shows number of pregnant patients based on pregnancy trimester. X axis represents the pregnancy trimester and $\mathrm{Y}$ axis represents the total number of pregnant patients. Among 55 patients, Majority of the patients belong to the 2 nd trimester stage $(52.73 \%)$.

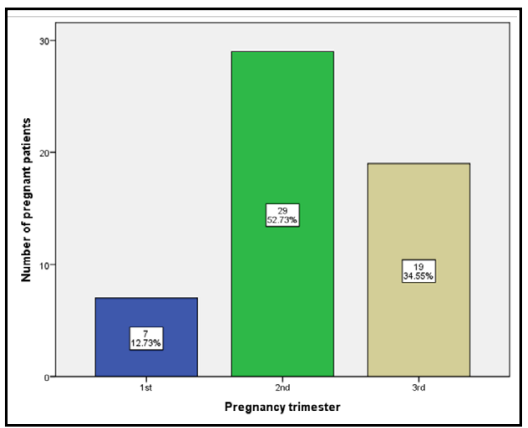

Figure 3. Bar Graph shows the association between the pregnancy trimester with presence/absence of periodontal disease. $\mathrm{X}$ axis represents the presence or absence of periodontal disease and $\mathrm{Y}$ axis represents the total number of pregnant patients. Among 55 patients, higher prevalence of periodontal disease was found among pregnant patients in the second trimester stage $(40 \%)$ than other stages. $P$ value $=0.024(p<0.05)$ hence statistically significant.

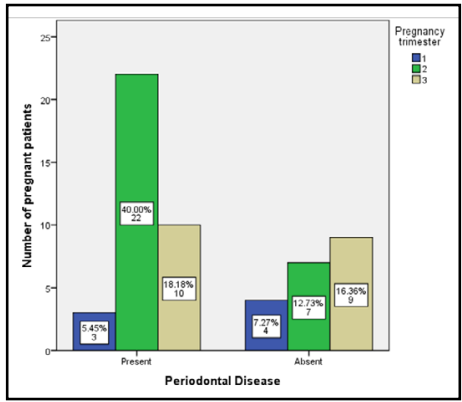

Figure 4. Bar Graph shows the association between age groups and presence/absence of periodontal disease. $\mathrm{X}$ axis represents the age and $\mathrm{Y}$ axis represents the total number of pregnant patients. Higher prevalence of periodontal disease was seen in pregnant patients of age group $26-30$ years $(29.09 \%)$ than other age groups. $p$ value $=0.041(p<0.05)$, hence statistically significant.

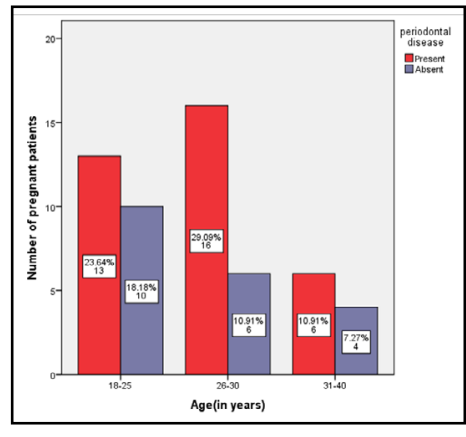

affected with periodontal disease than other age groups and the results obtained are statistically significant $\mathrm{p}$ value:0.041 $(\mathrm{p}<0.05)$ proving the association between age group and periodontal disease (Figure 4).

A clinical study conducted by neil et al proves the presence of chronic gingivitis during pregnancy confirmed in a group of 24 pregnant patients when observed at the 14th and 30th weeks of pregnancy. On in vitro examination, a depression in the maternal $t$ cell response was observed and indicates the important factor responsible for the altered responsiveness of gingival tissues [9].

A Study conducted by figuero et al produced experimental gingivitis in a group of pregnant women, allowing the accumulation of plaque and observing that the plaque index was highly similar among the different phases. The author concluded that the gingivitis in the pregnant woman was due in part to physiological vascular phenomena induced by increased estrogen and progesterone levels and in part to bacterial plaque [26].
Another study conducted by Gonzalez et al says that the periodontal status of pregnant women who already have some periodontal symptoms worsens with the progression of their pregnancy, reflected in the gingival bleeding and periodontal depth findings [27]. Our institution is passionate about high quality evidence based research and has excelled in various fields [28-38].

The limitations of the study were that inadequate sample size and the study was unicentered and predominantly included the south indian population.

Further studies about pregnancy and periodontal outcomes will help to prevent the difficulties faced by women during pregnancy, it is significant to understand the importance of pregnancy related oral issues and proper training should be given and health programmes should be conducted to educate the women to maintain their oral hygiene in order to avoid pregnancy complications. 


\section{Conclusion}

Within the limits of this study of association of periodontal disease and pregnant women, women who were in the 2nd trimester were more prevalent to have association with periodontal disease than other stages of pregnancy and pregnant women of age group 26-30 years had more association with periodontal disease than other age groups. There is a significant relationship between periodontal disease and pregnant women. Thus it is important for the dentists to advise the pregnant patients to maintain their oral hygiene to avoid unnecessary complications and also provide proper oral hygiene instructions during the course of their pregnancy period.

\section{Acknowledgement}

The authors would like to thank Saveetha Dental College and Hospitals for providing the platform to conduct the study.

\section{References}

[1]. Löe H, Silness J. Periodontal disease in pregnancy I. Prevalence and severity. Acta Odontol Scand. 1963 Jan 1;21(6):533-51.

[2]. Xiong X, Buekens P, Fraser WD, Beck J, Offenbacher S. Periodontal disease and adverse pregnancy outcomes: a systematic review. BJOG: Int. J. Gynecol. Obstet. 2006 Feb;113(2):135-43.

[3]. Bobetsis YA, Barros SP, Offenbacher S. Exploring the relationship between periodontal disease and pregnancy complications. J. Am. Dent. Assoc. 2006 Oct 1;137:S7-13S.

[4]. Dasanayake AP. Poor periodontal health of the pregnant woman as a risk factor for low birth weight. Ann Periodontol. 1998 Jul;3(1):206-12.

[5]. Offenbacher S, Katz V, Fertik G, Collins J, Boyd D, Maynor G, et al. Periodontal infection as a possible risk factor for preterm low birth weight. J Periodontol. 1996 Oct;67:1103-13.

[6]. Subashri A, Maheshwari TN. Knowledge and attitude of oral hygiene practice among dental students. Res J Pharm Technol. 2016;9(11):1840-2.

[7]. Cohen DW, Friedman L, Shapiro J, Kyle GC. A longitudinal investigation of the periodontal changes during pregnancy. J. Periodontol. 1969 Oct; $40(10): 563-70$.

[8]. Brabin BJ. Epidemiology of infection in pregnancy. Rev. Infect. Dis. 1985 Sep 1;7(5):579-603.

[9]. O'Neil TC. Maternal T-lymphocyte response and gingivitis in pregnancy. J Periodontol. 1979 Apr;50(4):178-84.Pubmed PMID: 312316.

[10]. Chaitanya NC, Muthukrishnan A, Krishnaprasad CMS, Sanjuprasanna G, Pillay P, Mounika B. An Insight and Update on the Analgesic Properties of Vitamin C. J Pharm Bioallied Sci. 2018 Jul-Sep;10(3):119-125.Pubmed PMID: 30237682.

[11]. Hafeez N. Accessory foramen in the middle cranial fossa. Res J Pharm Technol. 2016;9(11):1880-2.

[12]. Krishnan RP, Ramani P, Sherlin HJ, Sukumaran G, Ramasubramanian A, Jayaraj G, et al. Surgical Specimen Handover from Operation Theater to Laboratory: A Survey. Ann Maxillofac Surg. 2018 Jul-Dec;8(2):234-238. Pubmed PMID: 30693238.

[13]. Somasundaram S, Ravi K, Rajapandian K, Gurunathan D. Fluoride Content of Bottled Drinking Water in Chennai, Tamilnadu. J Clin Diagn Res. 2015 Oct;9(10):ZC32-4.Pubmed PMID: 26557612.

[14]. Felicita AS. Orthodontic extrusion of Ellis Class VIII fracture of maxillary lateral incisor - The sling shot method. Saudi Dent J. 2018 Jul;30(3):265269.Pubmed PMID: 29942113.

[15]. Kumar S, Rahman R. Knowledge, awareness, and practices regarding biomedical waste management among undergraduate dental students. Asian J Pharm Clin Res.. 2017;10(8):341.

[16]. Gurunathan D, Shanmugaavel AK. Dental neglect among children in Chennai. J Indian Soc Pedod Prev Dent. 2016 Oct 1;34(4):364.

[17]. Sneha S, Others. Knowledge and awareness regarding antibiotic prophylaxis for infective endocarditis among undergraduate dental students. Asian Journal of Pharmaceutical and Clinical Research. 2016;154-9.

[18]. Dhinesh B, Lalvani JI, Parthasarathy M, Annamalai K. An assessment on performance, emission and combustion characteristics of single cylinder diesel engine powered by Cymbopogon flexuosus biofuel. Energy Convers. Manag. 2016 Jun 1;117:466-74.

[19]. Choudhari S, Thenmozhi MS. Occurrence and Importance of Posterior Condylar Foramen. Res J Pharm Technol. 2016;9(8): 11-43.

[20]. Paramasivam A, Vijayashree Priyadharsini J, Raghunandhakumar S. N6adenosine methylation $(\mathrm{m} 6 \mathrm{~A})$ : a promising new molecular target in hypertension and cardiovascular diseases. Hypertens Res. 2020 Feb;43(2):153154.Pubmed PMID: 31578458.

[21]. Wu F, Zhu J, Li G, Wang J, Veeraraghavan VP, Krishna Mohan S, et al. Biologically synthesized green gold nanoparticles from Siberian ginseng induce growth-inhibitory effect on melanoma cells (B16). Artif Cells Nanomed Biotechnol. 2019 Dec;47(1):3297-3305.Pubmed PMID: 31379212.

[22]. Palati S, Ramani P, Shrelin HJ, Sukumaran G, Ramasubramanian A, Don $\mathrm{KR}$, et al. Knowledge, Attitude and practice survey on the perspective of oral lesions and dental health in geriatric patients residing in old age homes. Indian J Dent Res. 2020 Jan-Feb;31(1):22-25.Pubmed PMID: 32246676.

[23]. Saravanan M, Arokiyaraj S, Lakshmi T, Pugazhendhi A. Synthesis of silver nanoparticles from Phenerochaete chrysosporium (MTCC-787) and their antibacterial activity against human pathogenic bacteria. Microb Pathog. 2018 Apr;117:68-72.Pubmed PMID: 29427709.

[24]. Govindaraju L, Gurunathan D. Effectiveness of Chewable Tooth Brush in Children-A Prospective Clinical Study. J Clin Diagn Res. 2017 Mar;11(3):ZC31-ZC34.Pubmed PMID: 28511505.

[25]. Vijayakumar Jain S, Muthusekhar MR, Baig MF, Senthilnathan P, Loganathan S, Abdul Wahab PU, et al. Evaluation of Three-Dimensional Changes in Pharyngeal Airway Following Isolated Lefort One Osteotomy for the Correction of Vertical Maxillary Excess: A Prospective Study. J Maxillofac Oral Surg. 2019 Mar;18(1):139-146.Pubmed PMID: 30728705.

[26]. Figuero E, Carrillo-de-Albornoz A, Martín C, Tobías A, Herrera D. Effect of pregnancy on gingival inflammation in systemically healthy women: a systematic review. J. Clin. Periodontol. 2013 May;40(5):457-73.

[27]. González-Jaranay M, Téllez L, Roa-López A, Gómez-Moreno G, Moreu G. Periodontal status during pregnancy and postpartum. PloS one. 2017 May 19;12(5):e0178234.

[28]. Vijayashree Priyadharsini J. In silico validation of the non-antibiotic drugs acetaminophen and ibuprofen as antibacterial agents against red complex pathogens. J Periodontol. 2019 Dec;90(12):1441-1448.Pubmed PMID: 31257588.

[29]. Pc J, Marimuthu T, Devadoss P, Kumar SM. Prevalence and measurement of anterior loop of the mandibular canal using CBCT: A cross sectional study. Clin Implant Dent Relat Res. 2018 Apr 6;20(4):531-4.

[30]. Ramesh A, Varghese S, Jayakumar ND, Malaiappan S. Comparative estimation of sulfiredoxin levels between chronic periodontitis and healthy patients - A case-control study. J Periodontol. 2018 Oct;89(10):1241-1248.Pubmed PMID: 30044495.

[31]. Ramadurai N, Gurunathan D, Samuel AV, Subramanian E, Rodrigues SJ. Effectiveness of 2\% Articaine as an anesthetic agent in children: randomized controlled trial. Clin Oral Investig. 2019 Sep;23(9):3543-50.

[32]. Sridharan G, Ramani P, Patankar S, Vijayaraghavan R. Evaluation of salivary metabolomics in oral leukoplakia and oral squamous cell carcinoma. J Oral Pathol Med. 2019 Apr;48(4):299-306.

[33]. Ezhilarasan D, Apoorva VS, Ashok Vardhan N. Syzygium cumini extract induced reactive oxygen species-mediated apoptosis in human oral squamous carcinoma cells. J Oral Pathol Med. 2019 Feb;48(2):115-121.Pubmed PMID: 30451321.

[34]. Mathew MG, Samuel SR, Soni AJ, Roopa KB. Evaluation of adhesion of Streptococcus mutans, plaque accumulation on zirconia and stainless steel crowns, and surrounding gingival inflammation in primary molars: randomized controlled trial. Clin Oral Investig. 2020 Sep;24(9):1-6.Pubmed PMID: 31955271.

[35]. Samuel SR. Can 5-year-olds sensibly self-report the impact of developmental enamel defects on their quality of life? Int J Paediatr Dent. 2021 Mar;31(2):285-286.Pubmed PMID: 32416620.

[36]. R H, Ramani P, Ramanathan A, R JM, S G, Ramasubramanian A, et al. CYP2 C9 polymorphism among patients with oral squamous cell carcinoma and its role in altering the metabolism of benzo[a]pyrene. Oral Surg Oral Med Oral Pathol Oral Radiol. 2020 Sep;130(3):306-312.Pubmed PMID: 32773350 .

[37]. Chandrasekar R, Chandrasekhar S, Sundari KKS, Ravi P. Development and validation of a formula for objective assessment of cervical vertebral bone age. Prog Orthod. 2020 Oct 12;21(1):38.Pubmed PMID: 33043408.

[38]. Vijayashree Priyadharsini J, Smiline Girija AS, Paramasivam A. In silico analysis of virulence genes in an emerging dental pathogen A. baumannii and related species. Arch Oral Biol. 2018 Oct;94:93-98.Pubmed PMID: 30015217. 